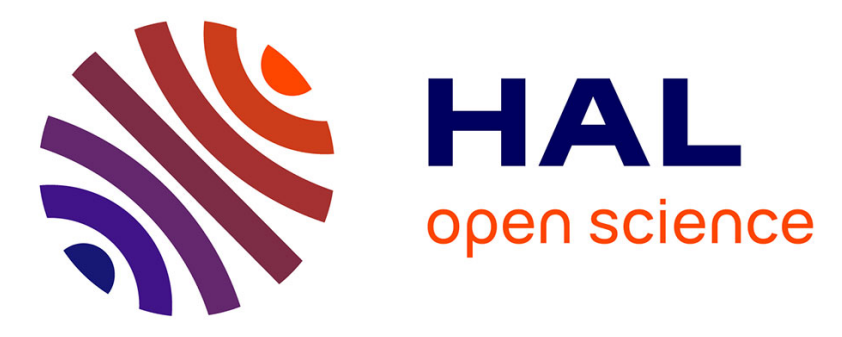

\title{
Does flame-generated vorticity increase turbulent burning velocity?
}

Andrei N. Lipatnikov, Vladimir Sabelnikov, Shinnosuke Nishiki, Tatsuya Hasegawa

\section{- To cite this version:}

Andrei N. Lipatnikov, Vladimir Sabelnikov, Shinnosuke Nishiki, Tatsuya Hasegawa. Does flamegenerated vorticity increase turbulent burning velocity?. Physics of Fluids, 2018, 30, pp.081702. 10.1063/1.5046137 . hal-02068663

\section{HAL Id: hal-02068663 https://hal.science/hal-02068663}

Submitted on 15 Mar 2019

HAL is a multi-disciplinary open access archive for the deposit and dissemination of scientific research documents, whether they are published or not. The documents may come from teaching and research institutions in France or abroad, or from public or private research centers.
L'archive ouverte pluridisciplinaire HAL, est destinée au dépôt et à la diffusion de documents scientifiques de niveau recherche, publiés ou non, émanant des établissements d'enseignement et de recherche français ou étrangers, des laboratoires publics ou privés. 


\title{
- Does Flame-Generated Vorticity Increase Turbulent Burning Velocity?
}

\author{
A.N. Lipatnikov, ${ }^{1, a)}$ V.A. Sabelnikov, ${ }^{2,}{ }^{3}$ S. Nishiki, ${ }^{4}$ and T. Hasegawa ${ }^{5}$ \\ 1) Department of Mechanics and Maritime Sciences, Chalmers University of Technology, \\ Gothenburg, 412 96, Sweden \\ 2) ONERA - The French Aerospace Lab., F-91761 Palaiseau, \\ France \\ ${ }^{3)}$ Central Aerohydrodynamic Institute (TsAGI), 140180 Zhukovsky, Moscow Region, \\ Russian Federation \\ 4) Department of Mechanical Engineering, Kagoshima University, Kagoshima 890-0065, \\ Japan \\ ${ }^{5)}$ Institute of Materials and Systems for Sustainability, Nagoya University, \\ Nagoya 464-8603, Japan
}

(Dated: 19 June 2018)

Direct Numerical Simulation data obtained from a statistically stationary, 1D, planar, weakly turbulent, premixed flame, which is associated with the flamelet combustion regime, are analyzed in order to show that generation of vorticity due to baroclinic torque within flamelets can impede wrinkling the reaction surface, reduce its area, and decrease burning rate. These data call for revisiting the widelyaccepted concept of combustion acceleration due to flame-generated turbulence.

PACS numbers: 47.70.Fw, 82.33.Vx, 47.27.-i

Keywords: premixed turbulent burning, flame-generated turbulence, thermal expansion, combustion acceleration, DNS

The problem of the influence of combustion-induced thermal expansion on turbulent flow within a premixed flame brush has been challenging the combustion community for decades. The problem was posed by Karlovitz et al. ${ }^{1}$ and by Scurlock and Grover ${ }^{2}$ who introduced a concept of flame-generated turbulence in order to explain unexpectedly high burning rates obtained in some early experiments. Since that pioneering work, the thermal expansion effects were in the focus of research into turbulent combustion, but progress in modeling them has yet been rather moderate, as reviewed elsewhere. ${ }^{3-5}$ Nevertheless, the concept $t^{1,2}$ of combustion acceleration due to flame-generated turbulence has never been disputed, to the best of the present authors' knowledge, at least in the case of weak or moderate turbulence associated with a well-pronounced increase ${ }^{6}$ in burning rate by the rms turbulent velocity $u^{\prime}$. The present letter aims at putting this widely-accepted concept into question by showing that flame-generated vorticity can smooth wrinkles of the local flame surface, thus, reducing its area and, consequently, decreasing turbulent burning velocity $U_{t}$.

For this purpose, Direct Numerical Simulation (DNS) data ${ }^{7,8}$ will be analyzed. Since the data were comprehensively discussed by various research groups, ${ }^{7-23}$ we will restrict ourselves to a brief summary of those compressible simulations. They dealt with statistically planar, 1D, adiabatic flames modeled by unsteady 3D continuity, Navier-Stokes, and energy equations, as well as the ideal gas state equation. Combustion chemistry was reduced to a single reaction. The Lewis and Prandtl numbers were equal to 1.0 and 0.7 , respectively. The mixture state was characterized with a single combustion progress variable $c=\left(T-T_{u}\right) /\left(T_{b}-T_{u}\right)$. Temperature-dependence of molecular transport coefficients was taken into account, e.g., the kinematic viscosity $\nu=\nu_{u}\left(T / T_{u}\right)^{0.7}$. Here, $T$ is the temperature, subscripts $u$ and $b$ designate unburned reactants and burned products, respectively.

The computational domain was a rectangular box $\Lambda_{x} \times \Lambda_{y} \times \Lambda_{z}$, where $\Lambda_{x}=8 \mathrm{~mm}$ and $\Lambda_{y}=\Lambda_{z}=4 \mathrm{~mm}$. It was resolved using a uniform rectangular $(2 \Delta x=\Delta y=\Delta z)$ mesh of $512 \times 128 \times 128$ points. The flow was periodic in $y$ and $z$ directions.

a)Electronic mail: lipatn@chalmers.se. 

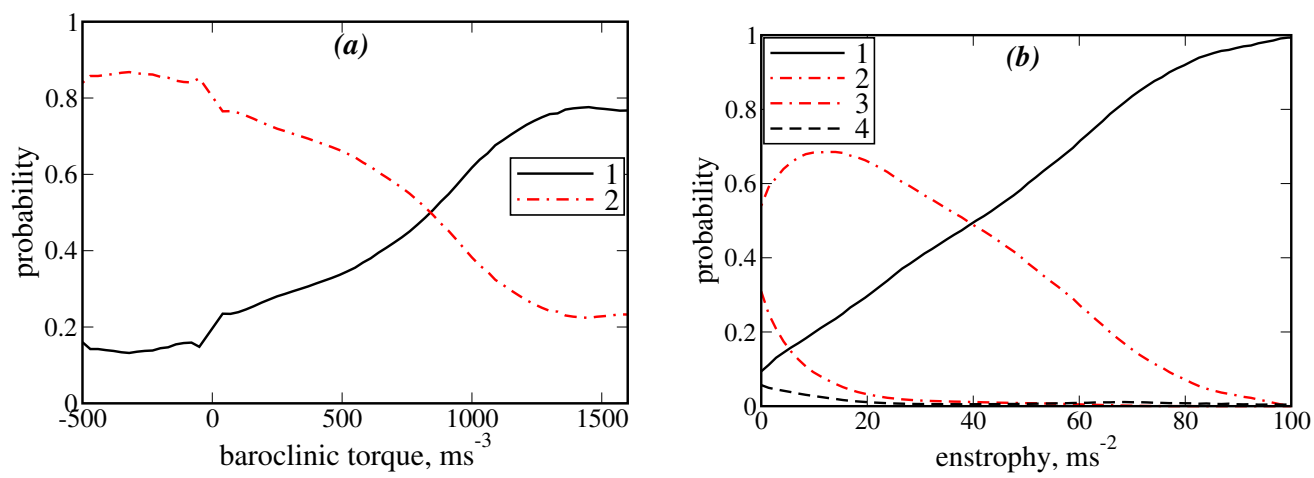

FIG. 1. Probabilities of negative (curves 1 and 4) and positive (curves 2 and 3) stretch rates conditioned on the local value of (a) baroclinic torque term $\boldsymbol{\omega} \cdot(\nabla \rho \times \nabla p) / \rho^{2}$ in the transport equation for the enstrophy $\Omega=\boldsymbol{\omega} \cdot \boldsymbol{\omega}$ and (b) enstrophy. In sub-figure (b), curves 1-2 and 3-4 are associated with the positive and negative, respectively, baroclinic torque term.

As discussed elsewhere ${ }^{7}$ homogeneous isotropic turbulence $\left(u^{\prime}=0.53 \mathrm{~m} / \mathrm{s}\right.$, an integral length scale $L=3.45 \mathrm{~mm}$, and the turbulent Reynolds number $R e_{t}=u^{\prime} L / \nu_{u}=96$ ) was generated in a separate box and was injected into the computational domain through its left boundary $x=0$. At $t=0$, a planar laminar flame was embedded into statistically the same turbulence assigned for the velocity field in the entire computational domain. Subsequently, the mean inflow velocity $U$ was increased twice, at $t=t_{1}$ and $t=t_{2}$, in order to keep the flame in the computational domain till the end $t_{3}$ of the simulations.

Three cases characterized by different density ratios $\sigma=\rho_{u} / \rho_{b}$ were studied. In the present letter, we will restrict ourselves to results obtained in a single case $\mathrm{H}$, characterized by the largest $\sigma=7.53$, because significant amount of flame-generated vorticity was documented in this case. ${ }^{15}$ As shown elsewhere ${ }^{16}$ premixed turbulent flame $\mathrm{H}$ (the laminar flame speed $S_{L}=0.6 \mathrm{~m} / \mathrm{s}$ and thickness $\left.\delta_{L}=\left(T_{b}-T_{u}\right) / \max \{|\nabla T|\}=0.217 \mathrm{~mm}\right)$ is well associated with the flamelet combustion regime. ${ }^{24,25}$

Figure 1 shows that the probability of negative (curves 1 and 4) stretch rates $^{26} \dot{s}=$ $\nabla \cdot \boldsymbol{u}-\boldsymbol{n} \boldsymbol{n}: \boldsymbol{u}+S_{d} \nabla \boldsymbol{n}$ is higher than the probability of $\dot{s}>0$ (curves 2 and 3) in regions characterized by a large magnitude of the local enstrophy $\Omega=\boldsymbol{\omega} \cdot \boldsymbol{\omega}$ or the local baroclinic torque term $\mathrm{T}_{b t}=\boldsymbol{\omega} \cdot(\nabla \rho \times \nabla p) / \rho^{2}$ in the transport equation ${ }^{15}$ for the enstrophy. Note that the relation between the two probabilities is opposite if the entire flame brush is considered. Here, $\boldsymbol{u}$ is the velocity vector, $\boldsymbol{n}=-\nabla c /|\nabla c|$ is the unit vector locally normal to an iso-scalar surface of $c(\boldsymbol{x}, t)=$ const, $\boldsymbol{\omega}=\nabla \times \boldsymbol{u}$ is the vorticity vector, $p$ is the pressure, $S_{d}=[\nabla \cdot(\rho D \nabla c)+W] /(\rho|\nabla c|)$ is the local displacement speed, $D$ is the molecular diffusivity of $c$, and $W$ is the mass rate of product creation.

Since the rate $A_{F}^{-1} d A_{F} / d t$ of an increase or decrease in the logarithm of an infinitesimal area $A_{F}$ of a propagating surface is equal to the local stretch rate ${ }^{26}$ Fig. 1 indicates that the area of a surface of $c(\boldsymbol{x}, t)=$ const is statistically reduced in regions associated with the strongest generation of vorticity and enstrophy due to the baroclinic torque.

This trend is further supported in Fig. 2, which shows that (a) relative (in volumes characterized by $\mathrm{T}_{1}<\mathrm{T}_{b t}<\mathrm{T}_{2}$ when compared to the entire flame brush) mean bulk rate

$$
\left\langle\delta A_{F} \mid c_{1}<c<c_{2}, \mathrm{~T}_{1}<\mathrm{T}_{b t}<\mathrm{T}_{2}\right\rangle=\frac{\int_{t_{2}}^{t_{3}} \iiint \dot{s}|\nabla c| \Pi\left(c_{1}<c<c_{2}\right) \Pi\left(\mathrm{T}_{1}<\mathrm{T}_{b t}<\mathrm{T}_{2}\right) d \boldsymbol{x} d t}{\int_{t_{2}}^{t_{3}} \iiint \dot{s}|\nabla c| \Pi\left(c_{1}<c<c_{2}\right) d \boldsymbol{x} d t}
$$

of an increase in flame surface area and (b) the mean local rate

$$
\left\langle\frac{d \Sigma}{d t} \mid c_{1}<c<c_{2}, \mathrm{~T}_{1}<\mathrm{T}_{b t}<\mathrm{T}_{2}\right\rangle=\frac{\int_{t_{2}}^{t_{3}} \iiint \dot{s}|\nabla c| \Pi\left(c_{1}<c<c_{2}\right) \Pi\left(\mathrm{T}_{1}<\mathrm{T}_{b t}<\mathrm{T}_{2}\right) d \boldsymbol{x} d t}{\int_{t_{2}}^{t_{3}} \iiint \Pi\left(c_{1}<c<c_{2}\right) \Pi\left(\mathrm{T}_{1}<\mathrm{T}_{b t}<\mathrm{T}_{2}\right) d \boldsymbol{x} d t}
$$



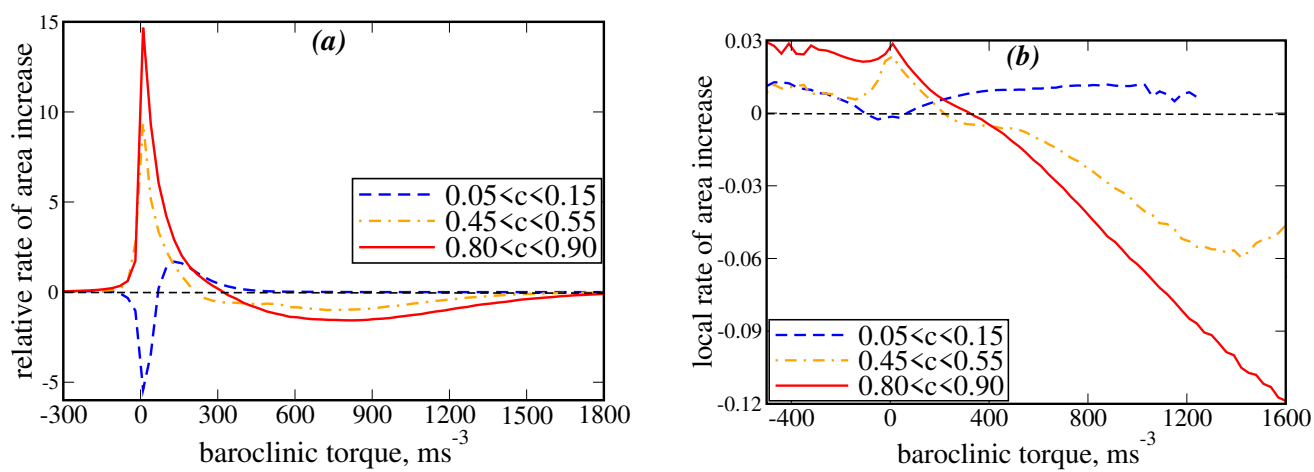

FIG. 2. (a) Relative bulk rate of an increase in flame surface area, given by Eq. (1), and (b) normalized local rate of an increase in flame surface area, given by Eq. (2), vs. baroclinic torque term $\boldsymbol{\omega} \cdot(\nabla \rho \times \nabla p) / \rho^{2}$ in the enstrophy transport equation. The rate is normalized using $\left(D_{u} / S_{L}^{2}\right)^{3}$.

of an increase in the area are negative in regions characterized by a high magnitude of the baroclinic torque term $\mathrm{T}_{b t}$ provided that the local value of $c(\boldsymbol{x}, t)$ is sufficiently large. Here, function $\Pi\left(q_{1}<q<q_{2}\right) \equiv H\left(q-q_{2}\right)-H\left(q-q_{1}\right)$ is equal to unity if $q_{1}<q<q_{2}$ and vanishes otherwise, $H(x)$ is Heaviside function, $\mathrm{T}_{b t}$-step $\mathrm{T}_{2}-\mathrm{T}_{1}=30 \mathrm{~ms}{ }^{-3}, \Sigma=|\nabla c|$ is flame surface density ${ }^{27}$ and the integral in the numerator of Eq. (1) or (2) characterizes the rate of an increase in flame surface area, because $d A_{F} / d t=\dot{s} A_{F}=\dot{s}|\nabla c| d V$.

The rates given by Eqs. (1) and (2) are predominantly positive in the vicinity of flamelet leading edge $(0.05<c<0.15)$, but becomes negative in the middle $(0.45<c<0.55)$ of flamelets and, especially, within flamelet's reaction zones $(0.80<c<0.90)$ provided that the magnitude of $\mathrm{T}_{b t}$ is sufficiently large. Therefore, vorticity generation by baroclinic torque within flamelet's preheat zones impedes increasing the area of the reaction zones and burning velocity, contrary to the common concept of flame-generated turbulence.

The fact that flame-generated vorticity can impede wrinkling flame surface is well-known in the theory of the hydrodynamic instability of laminar premixed flames. ${ }^{28}$ Within the framework of the theory, the incoming flow of unburned reactants is potential, but the rotational component of the velocity field is generated behind the flame and acts at smoothing flame-surface bulges, thus, reducing the destabilizing effect of the potential flow, e.g., see Eq. (40) in a recent review paper. ${ }^{4}$ Nevertheless, this classical theoretical result, which is qualitatively consistent with the present DNS data, has yet been beyond the mainstream discussion of the influence of flame-generated turbulence on burning rate.

Finally, it is worth stressing that the present letter does not claim that the influence of combustion-induced thermal expansion on turbulence reduces burning rate. The potential velocity perturbations can overwhelm the rotational perturbations and can result in increasing burning rate, as occurs in the case of a hydrodynamically unstable laminar premixed flame. ${ }^{28}$ However, if turbulence is considered to be inherently rotational flow, the concept of combustion acceleration due to flame-generated turbulence should be revisited. In particular, models developed for predicting an increase in burning rate by vorticity in the incoming turbulent flow are unlikely to be useful for describing a decrease in flamelet surface area and burning rate due to flame-generated vorticity. In other words, the influence of the incoming turbulence on burning rate should clearly be distinguished from the influence of flame-generated turbulence on the burning rate and the two effects can be opposite.

ANL gratefully acknowledges the financial support by the Chalmers Area of Advance Transport, and by the Combustion Engine Research Center (CERC). VAS gratefully acknowledges the financial support by ONERA and by the Grant of the Ministry of Education and Science of the Russian Federation (Contract No. 14.G39.31.0001 of 13.02.2017).

${ }^{1}$ B. Karlovitz, D. W. Denniston, and F. E. Wells, "Investigation of turbulent flames," J. Chem. Phys. 19, 541 (1951). 
${ }^{2}$ A. C. Scurlock and J. H. Grover, "Propagation of turbulent flames," Proc. Combust. Inst. 4, 645 (1953).

${ }^{3}$ R. Günther, "Turbulence properties of flames and their measurement," Prog. Energy Combust. Sci. 9, 105 (1983).

${ }^{4}$ A. N. Lipatnikov and J. Chomiak, "Effects of premixed flames on turbulence and turbulent scalar transport," Prog. Energy Combust. Sci. 36, 1 (2010).

${ }^{5}$ V. A. Sabelnikov and A. N. Lipatnikov, "Recent advances in understanding of thermal expansion effects in premixed turbulent flames," Annu. Rev. Fluid Mech. 49, 91 (2017).

${ }^{6}$ A. N. Lipatnikov and J. Chomiak, "Turbulent burning velocity and speed of developing, curved, and strained flames," Prog. Energy Combust. Sci. 28, 1 (2002).

${ }^{7}$ S. Nishiki, T. Hasegawa, R. Borghi, and R. Himeno, "Modeling of flame-generated turbulence based on direct numerical simulation databases," Proc. Combust. Inst. 29, 2017 (2002).

${ }^{8}$ S. Nishiki, T. Hasegawa, R. Borghi, and R. Himeno, "Modelling of turbulent scalar flux in turbulent premixed flames based on DNS databases," Combust. Theory Modelling 10, 39 (2006).

${ }^{9}$ Y. H. Im, K. Y. Huh, S. Nishiki, and T. Hasegawa, "Zone conditional assessment of flamegenerated turbulence with DNS database of a turbulent premixed flame," Combust. Flame 137, 478 (2004).

${ }^{10}$ A. Mura, K. Tsuboi, and T. Hasegawa, "Modelling of the correlation between velocity and reactive scalar gradients in turbulent premixed flames based on DNS data," Combust. Theory Modelling 12, 671 (2008).

${ }^{11}$ A. Mura, V. Robin, M. Champion, and T. Hasegawa, "Small scale features of velocity and scalar fields in turbulent premixed flames," Flow Turbul. Combust. 82, 339 (2009).

${ }^{12} \mathrm{~V}$. Robin, A. Mura, M. Champion, and T. Hasegawa, "Direct and indirect thermal expansion effects in turbulent premixed flames," Combust. Sci. Technol. 182, 449 (2010).

${ }^{13} \mathrm{~V}$. Robin, A. Mura, and M. Champion, "Modeling of the effects of thermal expansion on scalar turbulent fluxes in turbulent premixed flames," J. Fluid Mech. 689, 149 (2011).

${ }^{14}$ K. N. C. Bray, M. Champion, P. A. Libby, and N. Swaminathan, "Scalar dissipation and mean reaction rates in premixed turbulent combustion," Combust. Flame 158, 2017 (2011).

${ }^{15}$ A. N. Lipatnikov, S. Nishiki, and T. Hasegawa, "A direct numerical simulation study of vorticity transformation in weakly turbulent premixed flames," Phys. Fluids 26, 105104 (2014).

${ }^{16}$ A. N. Lipatnikov, S. Nishiki, and T. Hasegawa, "DNS assessment of relation between mean reaction and scalar dissipation rates in the flamelet regime of premixed turbulent combustion," Combust. Theory Modell. 19, 309 (2015).

${ }^{17}$ A. N. Lipatnikov, J. Chomiak, V. A. Sabelnikov, S. Nishiki, and T. Hasegawa, "Unburned mixture fingers in premixed turbulent flames," Proc. Combust. Inst. 35, 1401 (2015).

${ }^{18}$ A. N. Lipatnikov, V. A. Sabelnikov, S. Nishiki, T. Hasegawa, and N. Chakraborty, "DNS assessment of a simple model for evaluating velocity conditioned to unburned gas in premixed turbulent flames," Flow Turbul. Combust. 94, 513 (2015).

${ }^{19}$ V. A. Sabelnikov, A. N. Lipatnikov, N. Chakraborty, S. Nishiki, and T. Hasegawa, "A transport equation for reaction rate in turbulent flows," Phys. Fluids 28, 081701 (2016).

${ }^{20}$ V. A. Sabelnikov, A. N. Lipatnikov, N. Chakraborty, S. Nishiki, and T. Hasegawa, "A balance equation for the mean rate of product creation in premixed turbulent flames," Proc. Combust. Inst. 36, 1893 (2017).

${ }^{21}$ A. N. Lipatnikov, V. A. Sabelnikov, S. Nishiki, and T. Hasegawa, "Flamelet perturbations and flame surface density transport in weakly turbulent premixed combustion," Combust. Theory Modell. 21, 205 (2017).

${ }^{22}$ A. N. Lipatnikov, V. A. Sabelnikov, N. Chakraborty, S. Nishiki, and T. Hasegawa, "A DNS study of closure relations for convection flux term in transport equation for mean reaction rate in turbulent flow," Flow Turbul. Combust. 100, 75 (2018).

${ }^{23}$ A. N. Lipatnikov, J. Chomiak, V. A. Sabelnikov, S. Nishiki, and T. Hasegawa, "A DNS study of the physical mechanisms associated with density ratio influence on turbulent burning velocity in premixed flames," Combust. Theory Modell. 22, 131 (2018).

${ }^{24}$ R. Borghi, "Turbulent combustion modeling," Prog. Energy Combust. Sci. 14, 245 (1988).

${ }^{25}$ N. Peters, Turbulent Combustion (Cambridge University Press, Cambridge, UK, 2000).

${ }^{26} \mathrm{~S}$. Candel and T. Poinsot, "Flame stretch and the balance equation for the flame area," Combust. Sci. and Tech. 170, 1 (1990).

${ }^{27}$ D. Veynante and L. Vervisch, "Turbulent combustion modeling," Prog. Energy Combust. Sci. 28, 193 (2002).

${ }^{28}$ L. D. Landau and E. M. Lifshitz, Fluid Mechanics (Pergamon Press, Oxford, UK, 1987). 